\title{
Longitudinal determination of mRNA-vaccination induced strongly binding SARS-CoV-2 IgG antibodies in a cohort of healthcare workers with and without prior exposure to the novel coronavirus
}

\author{
Mónika Korodi, ${ }^{1,2}$ Kinga Rákosi,,${ }^{1,3}$ Zsuzsanna Jenei, ${ }^{1}$ Gabriella Hudák, ${ }^{1}$ István Horváth,,${ }^{1,2}$ Melinda Kákes, ${ }^{4}$ \\ Katalin Dallos-Fejér, ${ }^{1}$ Enikő Simai, ${ }^{4,5}$ Natalia Staver, ${ }^{4}$ Violeta Briciu, ${ }^{6,7}$ Mihaela Lupșe,${ }^{6,7}$ Mirela Flonta, ${ }^{6}$ \\ Ariana Almaș, ${ }^{6}$ Dana Pianoschi, ${ }^{6}$ Livia-Maria Terza, ${ }^{1}$ and Szilard N. Fejer ${ }^{1,2,8}$
}

1. Pro-Vitam Ltd., Muncitorilor street 16, Sfantu Gheorghe, Romania, 520032

2. Department of Chemistry, University of Pécs, Ifjúság street 6, Pécs, Hungary, 7624

3. Faculty of Technical and Human Sciences, Sapientia Hungarian University of Transylvania, Corunca 1c, Targu Mures, Romania, 540485

4. Promedical Center Ltd., Caisului street 16, Cluj-Napoca, Romania, 400487

5. Benedek Geza Hospital for Rehabilitation of Cardiovascular Disease, Mihai Eminescu street 160, Covasna, Romania, 525200

6. Hospital for Infectious Diseases Cluj-Napoca, Iuliu Moldovan street 23, Cluj-Napoca, Romania, 400348

7. Department of Infectious Diseases, University of Medicine and Pharmacy Iuliu Hatieganu, Iuliu Moldovan street 23, Cluj-Napoca, Romania, 400348

8. Proel Biotech Ltd., Muncitorilor street 16, Sfantu Gheorghe, Romania, 520032

\begin{abstract}
Background: Mass vaccination against the disease caused by the novel coronavirus (COVID-19) is a crucial step in slowing the spread of SARS-CoV-2. The BioNTech/Pfizer (BNT162b2) vaccine has been shown to induce strong immune responses among the vaccinated population. Measuring SARS-CoV-2 anti-spike protein IgG levels is a clinically convenient way to estimate post-vaccination humoral immune responses, but only limited data exists about its short- and long-term dynamics. We present a longitudinal analysis of post-vaccination IgG levels in a cohort of 122 healthcare workers vaccinated with BNT162b2 with weekly follow-up until 35 days past the first dose and results of the first monthly follow-up after that for a subset of these.

Methods: This prospective, multicenter cohort study consists of two periods for short-term and long-term evaluation of post-vaccination IgG levels. Tests were carried out on 666 samples from 122 participants, using in-house antispike 1 and anti-nucleocapsid IgG ELISA assays and a commercial, combined version of these.

Findings: Participants with previous SARS-CoV-2 infection mount a quick immune response, reaching peak $\operatorname{IgG}$ levels two weeks after vaccination. In contrast, the corresponding $\mathrm{IgG}$ levels for previously uninfected participants increase gradually, changing abruptly after the booster dose. Overall higher IgG levels are maintained for the previously infected group 35-70 days after vaccination, and we observe age-dependence of immune response as well.

Interpretation: Our results show a robust humoral immune response mounting gradually after the first vaccine dose for the uninfected group, and a much stronger immune response within 7-14 days after the first dose for the previously infected group.
\end{abstract}




\section{Introduction}

Vaccine-induced population immunity is an important step in defeating the 2019 novel coronavirus (2019$\mathrm{nCoV}$ )/severe acute respiratory syndrome coronavirus type 2 (SARS-CoV-2), and the coronavirus disease (COVID19). This virus is an enveloped single-stranded RNA virus, capable of human-to-human transmission. ${ }^{1}$ Immunoglobulin $\mathrm{G}(\mathrm{IgG})$ is a good biomarker in blood for detecting long-term immune response due to infections. ${ }^{2,3}$ Infected individuals mount very different immune responses, and the antibody levels that can be measured postinfection have a large variation. ${ }^{4-7}$ SARS-CoV-2 IgG antibody levels were found to correlate with disease severity. ${ }^{8}$ Patients with moderate and severe symptoms have on average larger quantities of detectable antibodies, ${ }^{9}$ while those with mild symptoms or asymptomatic infections mount a weaker immune response, measurable by lower quantities of antibodies which often decrease below the detection threshold in a couple of months. ${ }^{10}$ However, the relationship between SARS-CoV-2 IgG antibody quantities and the level of protection is not yet established, and is subject to intense research. It is assumed that a subset of these antibodies, those capable of neutralizing the virus by interfering with cell attachment, has the biggest role for protective immunity, while other types of antibodies either contribute to protective immunity through other mechanisms (removal of infected cells), ${ }^{11}, 12$ or cause long-term post-COVID complications. ${ }^{13}$ Experimental evidence for these mechanisms is scarce, and large observational follow-up studies are needed for determining any correlation between antibody levels and long-term protection from reinfection. The matter is further complicated by vaccination-induced antibodies. As COVID-19 vaccines have been widely approved from December 2020, only limited data exists on the dynamics of mounting immune response post-vaccination. Currently approved vaccines in the European Union contain instructions for cells to synthesize the SARS-CoV-2 spike protein, therefore the immune system will produce anti-SARS-CoV-2 spike antibodies ${ }^{14-16}$ while vaccine candidates that contain the full-length spike protein trimer are also in the pipeline. Several recent studies show a significant difference between post-vaccination immune response of previously infected individuals compared to uninfected vaccinated individuals, ${ }^{17-19}$ as the former group mounts a quick immune response within the first two weeks of the first vaccine dose, while the antibody titers of the non-infected group will be on average lower than those of the first group even 10 days after the second dose. ${ }^{18}$ However, much more data is needed to better understand the dynamics of post-vaccination antibody production in these two groups.

The BNT162b2 (Comirnaty) mRNA vaccine by BioNTech/Pfizer encodes the full-length transmembrane spike (S) glycoprotein, locked in its prefusion conformation by the substitution of two residues with proline. ${ }^{20}$ The available data shows that this vaccine had more than 90\% efficacy in preventing COVID-19 in phase III clinical trials, ${ }^{21-24}$ while large-scale monitoring of more than 500,000 vaccinated individuals in Israel supports the result of phase III observations. ${ }^{25}$

Here we present results for longitudinal monitoring of strongly binding SARS-CoV-2 IgG antibodies in a group of 122 healthcare workers post-vaccination with the BNT162b2 vaccine, with a strict monitoring regimen that results in high-resolution per-patient data for the first four weeks post-vaccination. A subset of these patients had their antibody levels determined about eight weeks post-vaccination as well. Antibodies produced against the SARS-CoV2 nucleocapsid $(\mathrm{N})$ and $\mathrm{S} 1$ domain of the spike protein were measured with separate in-house $\mathrm{N}$ and S1 enzymelinked immunosorbent (ELISA) assays, and a CE IVD marked commercial version of these (SARS-CoV-2 IgG antibody detection kit, Proel Biotech), which is a combined N+S1 ELISA assay, optimized for low background signal. These assays were conceived to detect only IgG antibodies that have high affinity to the target antigens.

\section{Methods}

\section{Study Design}

The results presented here are part of an ongoing prospective, multicenter cohort study aiming to monitor early and prolonged IgG production as a response to vaccination with the BNT162b2 COVID-19 vaccine. The study is carried out between January and June 2021 and consists of two periods. Period 1 lasted until two weeks past the second dose, with blood samples taken at one-week intervals to monitor the dynamics of early IgG production. We were aiming to collect four data points before the second dose, and at least one data point after the second dose from each participant. Period 2 will show the change in IgG levels 2-6 months after vaccination, with samples taken every four weeks, with the possibility of longer follow-up. 
The population of the study was recruited among healthcare worker volunteers from 5 different medical centers $(2$ public hospitals and 3 private outpatient centers involved in diagnosis and treatment of COVID-19 patients). Written and informed consent was obtained from all participants. The protocol was approved by the ethics committee of the Clinical Hospital of Infectious Diseases Cluj-Napoca. The enrolled subjects were scheduled for periodic venous blood sample collection, starting with the day of vaccination with the BNT162b2 vaccine for 5 weeks, and participants are followed up for at least 6 months.

The initial cohort consisted of 129 participants, from which 7 were excluded, as they did not meet the minimal study criteria of at least 3 sampling in Period 1, including at least one sample after 20 days of the first dose. 5 participants provided 4 samples, 68 participants 5 samples, 48 participants 6 samples, while 5 participants provided 7 or more samples. 58 participants $(47.5 \%)$ had blood samples taken 8 weeks after the initial vaccination, the results of which are included in this report. The total number of samples is 666 for 122 participants.

In total, we present the results for 122 participants, $100(82 \%)$ female. The participants were aged between 22 and 71 years, the median age was 44 years. The age distribution of participants is the following: 22 between 21-30, 28 between 31-40, 38 between 41-50, 21 between 51-60, 12 between 61-70 and 1 person aged between 71 and 80 years. 25 participants had tested previously positive for SARS-CoV-2 infection with RT-PCR between August and December 2020, one participant had a confirmed infection in April 2020. Distinctly, 18 more participants had close contacts with COVID-19 patients and also had symptoms consistent with the disease but were not tested with RTPCR. These healthcare workers had tested subsequently positive for SARS-CoV-2 IgG antibodies before getting vaccinated. The total number of confirmed previous SARS-CoV-2 infections is therefore 44 (36.1\%) within the study cohort.

The p-values between various groups were calculated with the ttest_lsamp and ttest_ind functions from the SciPy stats package. The average age and its standard deviation among healthcare workers in Romania was approximated based on data from the Statistical Yearbook of Romania for 2017 by using the reported middle values of the binned values and setting the maximum age to 80 . Plots were created with the Seaborn package of Python.

Table 1. Demographics of the study participants and the two groups (with and without prior record of infection). The calculated p-values show that each group can be considered representative for the population of healthcare workers in Romania, compared to statistical data from 2017. Group labels: inf - participants with prior record of infection, uninf - participants without prior record of infection, study - participants of the study, pop - population of Romanian healthcare workers according to the 2017 statistical yearbook.

\begin{tabular}{|l|l|l|l|l|l|l|l|}
\hline Characteristic & Uninfected & Infected & pstudy-pop & pinf-uninf & puninf-pop & pinf-pop & Population \\
\hline $\begin{array}{l}\text { Number of } \\
\text { participants }\end{array}$ & 78 & 44 & & & & & \\
\hline Gender (F) & $62(79.49 \%)$ & $\begin{array}{l}38 \\
(86.36 \%)\end{array}$ & 0.45 & 0.33 & 0.97 & 0.18 & $\begin{array}{l}\text { 79.3\% of people } \\
\text { working in Romanian } \\
\text { healthcare were female } \\
\text { (2017) }\end{array}$ \\
\hline $\begin{array}{l}\text { Age (years), } \\
\text { mean (SD) }\end{array}$ & $\begin{array}{l}44.29 \\
(12.96)\end{array}$ & $\begin{array}{l}43.55 \\
(10.73)\end{array}$ & 0.49 & 0.73 & 0.49 & 0.86 & $\begin{array}{l}\text { Avg. age of a person } \\
\text { working in healthcare } \\
\text { was 43.27 } \\
\text { (approximated from } \\
\text { 2017 statistics) }\end{array}$ \\
\hline
\end{tabular}


Development of the enzyme-linked immunosorbent (ELISA) assays

\section{1. $\quad$ Preparation of SARS-CoV-2 antigen coated plates}

The 96 well microplate (12x8 well strips on a single well holding plate frame, Greiner) was pre-activated at room temperature for 10 minutes with $50 \mu \mathrm{l} /$ well Coating buffer 1x (Coating Buffer 10x concentrate, CANDOR Bioscience $\mathrm{GmbH}$ ) - the 10x concentrate was diluted with deionized water to the appropriate concentration prior to use. After pre-activation, the content of the wells was completely aspirated. The microplates were coated with $50 \mu 1$ antigen of $1 \mu \mathrm{g} / \mathrm{ml}$ concentration in Coating buffer, incubated at $4^{\circ} \mathrm{C}$ overnight. The antigen used for the S1 plates was the SARS-CoV-2 Spike S1 protein (His tag) from Sanyoubio, the one for the N plates was the SARS-CoV-2 nucleocapsid protein (His tag) from Sanyoubio. After incubation, the content of the wells was completely aspirated and $350 \mu 1$ PlateBlock buffer (PlateBlock OEM, CANDOR Bioscience $\mathrm{GmbH}$ ) was added into each well of the microplate and incubated at room temperature for 2 hours, followed by aspirating the content of the wells. Antigens were preserved in their original conformation using $100 \mu \mathrm{l} /$ well Liquid Plate Sealer (Liquid Plate Sealer OEM, CANDOR Bioscience $\mathrm{GmbH}$ ) for each well, followed by incubation at room temperature for 90 minutes. After incubation, the content of the wells was completely aspirated. The coated plate was dried at $37^{\circ} \mathrm{C}$ by incubation for approximately 1 hour. The SARS-CoV-2 antigen coated plates were sealed with vacuum and stored at $4^{\circ} \mathrm{C}$. The preactivation, coating, blocking and sealing steps were carried out on an Opentrons OT-2 automated pipetting platform.

\section{Assay procedure}

Serum samples were diluted 1:101 with Sample diluent (LowCross-Buffer OEM, CANDOR Bioscience GmbH) and mixed by vortex. $50 \mu \mathrm{l}$ positive control (human serum containing anti-SARS-CoV-2 IgG antibodies) and negative control (human serum without anti-SARS-CoV-2 IgG antibodies) was added into the first two wells, the diluted samples were added into consecutive wells of the antigen-coated plate and incubated at room temperature for 1 hour in the dark. After incubation, the wells were washed 5 times with $350 \mu$ l diluted Wash buffer (Washing Buffer PBS 10X OEM, CANDOR Bioscience GmbH). $50 \mu$ l Enzyme Conjugate (Goat anti-Human IgG secondary antibody, Abcam, diluted 1:20.000 in LowCross HRP-Stab buffer, CANDOR Bioscience GmbH) was added and incubated at room temperature for 15 minutes in the dark. After incubation, the washing step described was repeated and $50 \mu 1$ TMB Substrate solution (SeramunBlau automat fast, Seramun Diagnostica $\mathrm{GmbH}$ ) was added into the wells, and another incubation step followed at room temperature for 20 minutes in the dark. After this incubation period, $25 \mu 1$ Stop solution $(0.25 \mathrm{~mol} / \mathrm{l}$ sulfuric acid, Merck) was added into the wells and the optical density values at 450 and 620 $\mathrm{nm}$ (or 450 and $630 \mathrm{~nm}$ ) were read on a microplate or microstrip reader (Adaltis Plab, StatFax 4700, StatFax 303+). The corrected optical density values $\left(\mathrm{OD}_{450}-\mathrm{OD}_{620 / 630}\right)$, normalized according to the intensity of the positive control on each plate, are reported here.

SARS-CoV-2 antibodies were also determined from the collected serum samples with a commercial version of the above-described ELISA assay, which includes both the S1 and nucleocapsid antigens coated on the microplate, and has been optimized for low background signal. The quantitative values were determined as a signal to cutoff ratio in arbitrary units (AU/ml), the cutoff was set to the optical density (OD) of the negative control plus $6 \mathrm{x}$ the standard deviation (total 0.1 OD) determined during product validation on 88 samples before February 2019. The assay showed $100 \%$ specificity, determined on 88 pre-pandemic serum samples, and $100 \%$ sensitivity compared to a chemiluminescent assay containing an antigen different than the SARS-CoV-2 N or S1 protein, for 30 COVID-19 recovered patients 1-3 months after diagnosis. For the measurements reported here with the commercial version of the assay, samples were tested on the day of collection or frozen and thawed only one time. Subsequently, all collected samples during Period 1 were stored at $-20^{\circ} \mathrm{C}$ and remeasured with the separate nucleocapsid and $\mathrm{S} 1$ assays in duplicates.

\section{Results}

Figure 1 shows the dynamics of determined IgG values for each included participant in signal to cutoff type units $(\mathrm{AU} / \mathrm{ml})$, grouped into previously infected and uninfected groups. Previous infection confirmed with RT-PCR is shown separately to seropositive participants with no known positive RT-PCR test. We observe two distinct patterns, with IgG values of the uninfected group well-separated from the other two groups within the first 21 days of 
medRxiv preprint doi: https://doi.org/10.1101/2021.03.17.21253751; this version posted March 24, 2021. The copyright holder for this preprint (which was not certified by peer review) is the author/funder, who has granted medRxiv a license to display the preprint in perpetuity. It is made available under a CC-BY-ND 4.0 International license .

vaccination. That separation is the most pronounced for data points acquired 12-16 days after the first vaccine dose. In line with other observations, the first vaccine dose for previously infected individuals acts as a booster dose, greatly increasing the detected antibody levels within a week. Only one, mildly symptomatic participant with a previous positive PCR test result behaved significantly differently from this group, showing a gradual mounting of immune response similar to the trends observed for previously uninfected individuals.

After the booster dose (day 21), an abrupt increase of $\operatorname{IgG}$ levels is observed for the previously uninfected group, while the change in antibody levels for the previously infected group is significantly more heterogenous, with a slight decrease observed for about the third of these participants. Nevertheless, at the end of Period 1 of the study, the average determined antibody levels for the previously infected group are significantly higher than those for the previously uninfected group.

Data obtained between 36-70 days post vaccination shows an overall slight decrease of $\operatorname{IgG}$ levels that is more evident in the previously uninfected group. The deviation observed between measured IgG values is also smaller for the last period, but this can be due to the much smaller sample size. One female participant from the previously uninfected group did not receive the booster dose, and her IgG level measured 63 days after vaccination got below the limit of detection, in the range of the assay that is interpreted as negative. Apart from this participant, we observe a single, previously uninfected weak responder to the vaccine, with peak $\mathrm{IgG}$ levels of only $1.51 \mathrm{AU} / \mathrm{ml}$ after the second dose, decreasing to 0.91 after 51 days post-vaccination ( $>0.9 \mathrm{AU} / \mathrm{ml}$, within the inconclusive range of the assay).

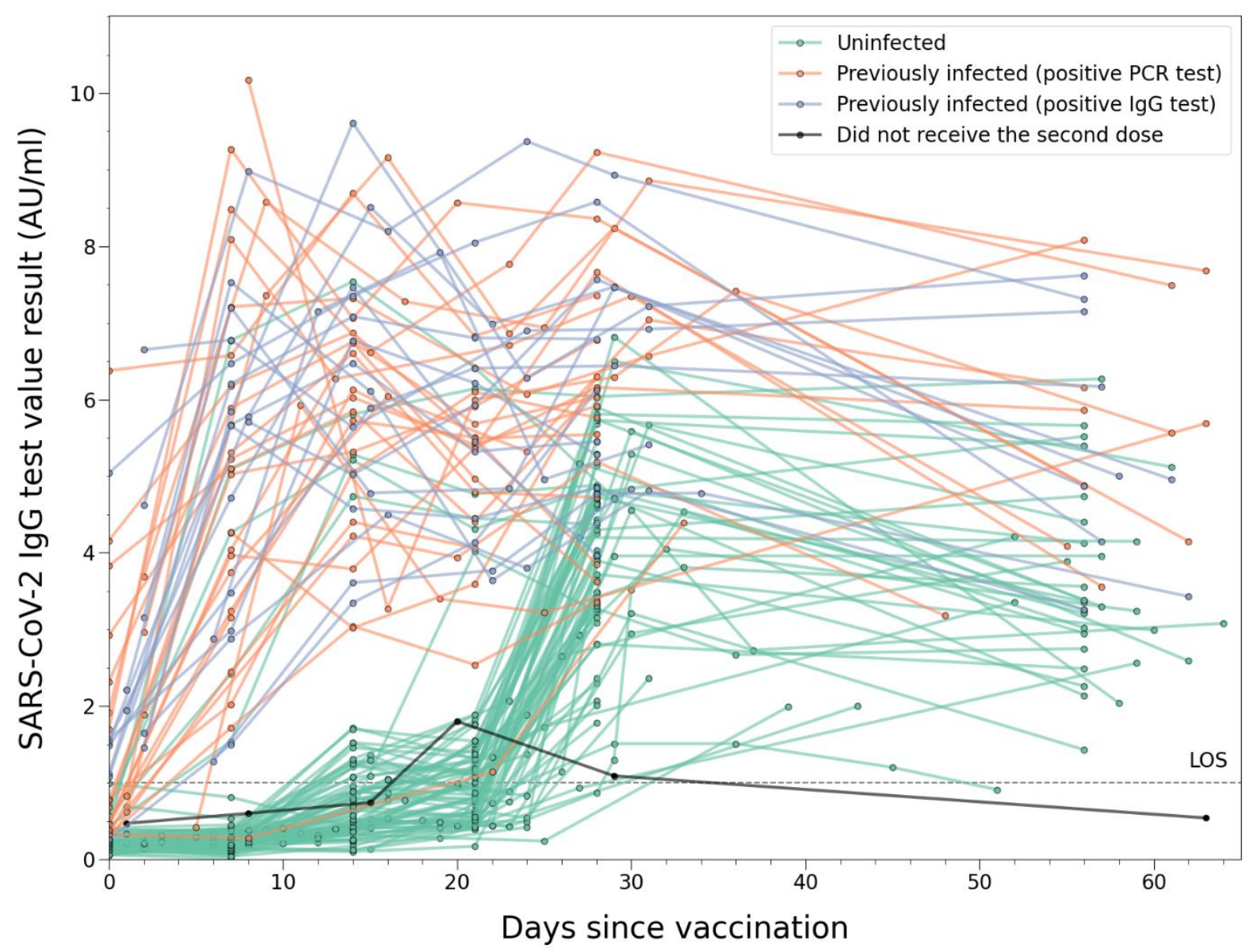

Figure 1. Dynamics of measured SARS-CoV-2 IgG values post-vaccination in the previously uninfected and previously infected groups. Lines connect data points obtained longitudinally from the same patient. 
medRxiv preprint doi: https://doi.org/10.1101/2021.03.17.21253751; this version posted March 24, 2021. The copyright holder for this preprint (which was not certified by peer review) is the author/funder, who has granted medRxiv a license to display the preprint in perpetuity. It is made available under a CC-BY-ND 4.0 International license .

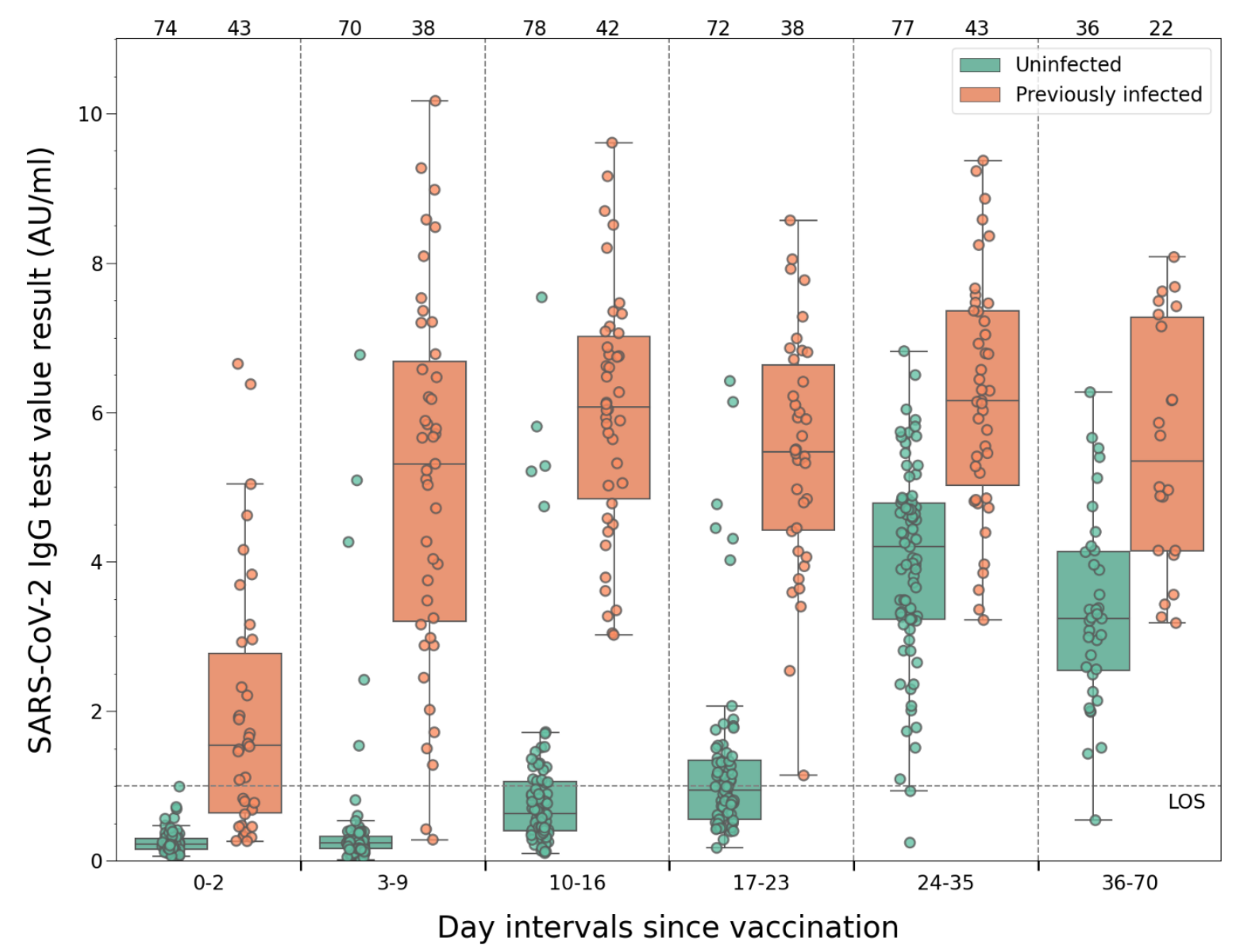

Figure 2. Distribution of measured SARS-CoV-2 IgG antibody levels at different time intervals post-vaccination with the first dose: baseline (0-2 days) and weekly intervals until the administration of the second dose. The fifth interval of 11 days shows the immune response after the second dose until the end of Period 1 of our study. Values measured for a subset of these patients are shown in the $6^{\text {th }}$ interval of 24 days. If multiple measurements were done for a participant within these intervals, only the largest value is shown. The limit of sensitivity (LOS) for the assay is $1 \mathrm{AU} / \mathrm{ml}$.

Figure 2 shows the determined SARS-CoV-2 anti-N + anti-S1 IgG antibody levels grouped by previous infection status, with samples grouped at baseline (0-2 days post-vaccination) and weekly intervals. The first 24 days of Period 2 is included as well as a single group. The different dynamics of antibody production for the two groups is evident, the corresponding determined intergroup p-values are tabulated in Supplementary Tables 1-3.

As the commercial ELISA assay detects both anti-N and anti-S1 IgG antibodies, we remeasured the samples with separate anti-N and anti-S1 in-house assays to observe the dynamics of the two antibody types individually for Period 1 of the study. Figure 3 shows the obtained per-participant plots and the corresponding box plots for the same intervals as in Figure 2. As expected, vaccination does not have an effect to observed anti-N levels, the longitudinal increase is due to vaccination-induced anti-S1 antibody production, with similar dynamics than that measured with the commercial assay, with the exception of the baseline (0-2 days) in the previously infected group, where we observe much lower quantities of strongly binding anti-S1 antibodies than anti-N antibodies. The difference between baseline antibody levels of the two groups, measured with the commercial version of the assay, is therefore mainly due to the presence of anti-N antibodies in the previously infected group. 
medRxiv preprint doi: https://doi.org/10.1101/2021.03.17.21253751; this version posted March 24, 2021. The copyright holder for this preprint (which was not certified by peer review) is the author/funder, who has granted medRxiv a license to display the preprint in perpetuity. It is made available under a CC-BY-ND 4.0 International license .
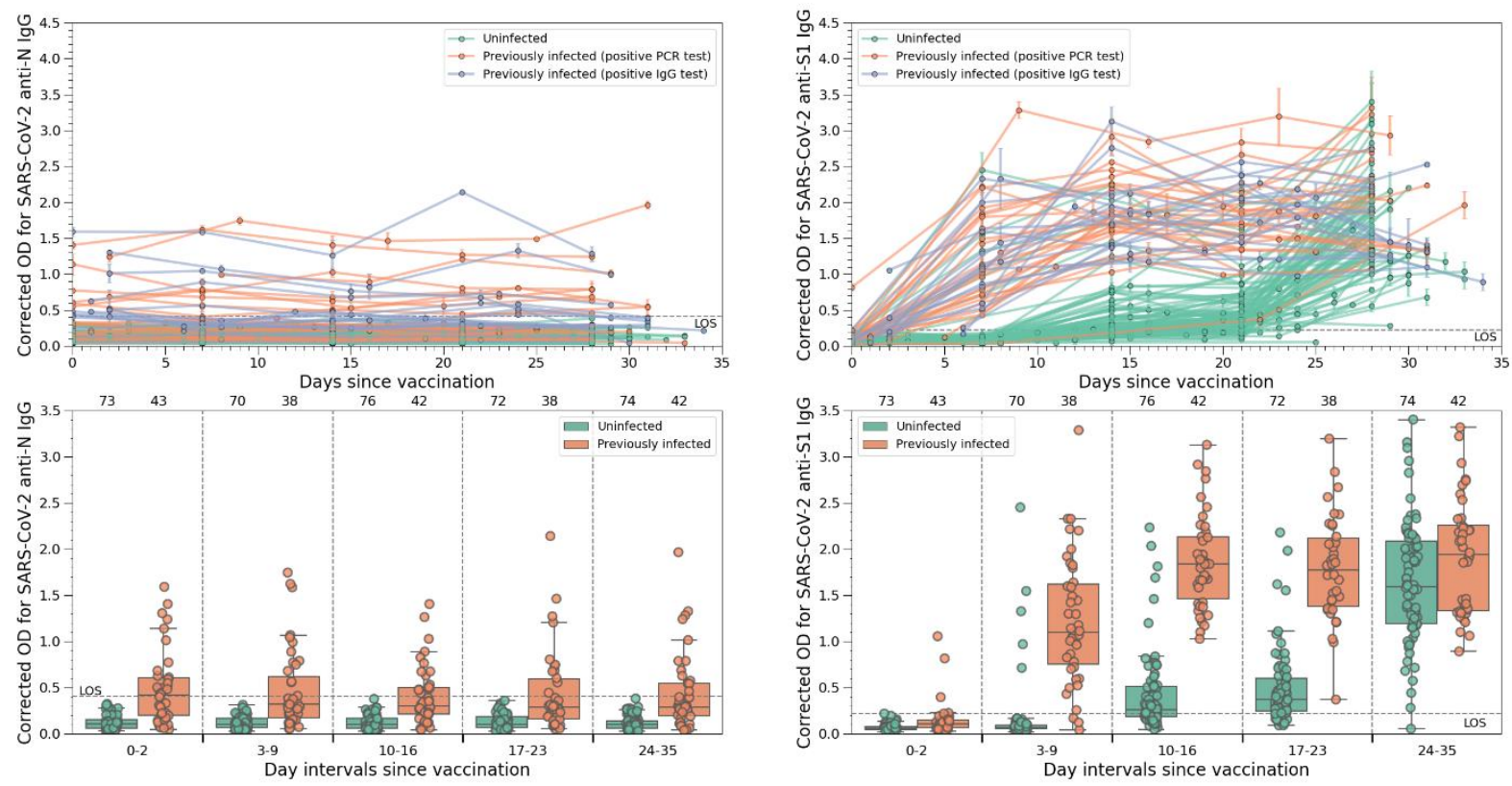

Figure 3. Dynamics of measured SARS-CoV-2 anti-N and anti-S1 IgG levels among the study participants over time for Period 1 of the study (0-35 days post-vaccination). The numbers on top of each box plot represent the number of samples within each group. Top column: anti-N IgG levels in optical density units (ODU), right column: anti-S1 IgG levels on the same scale.
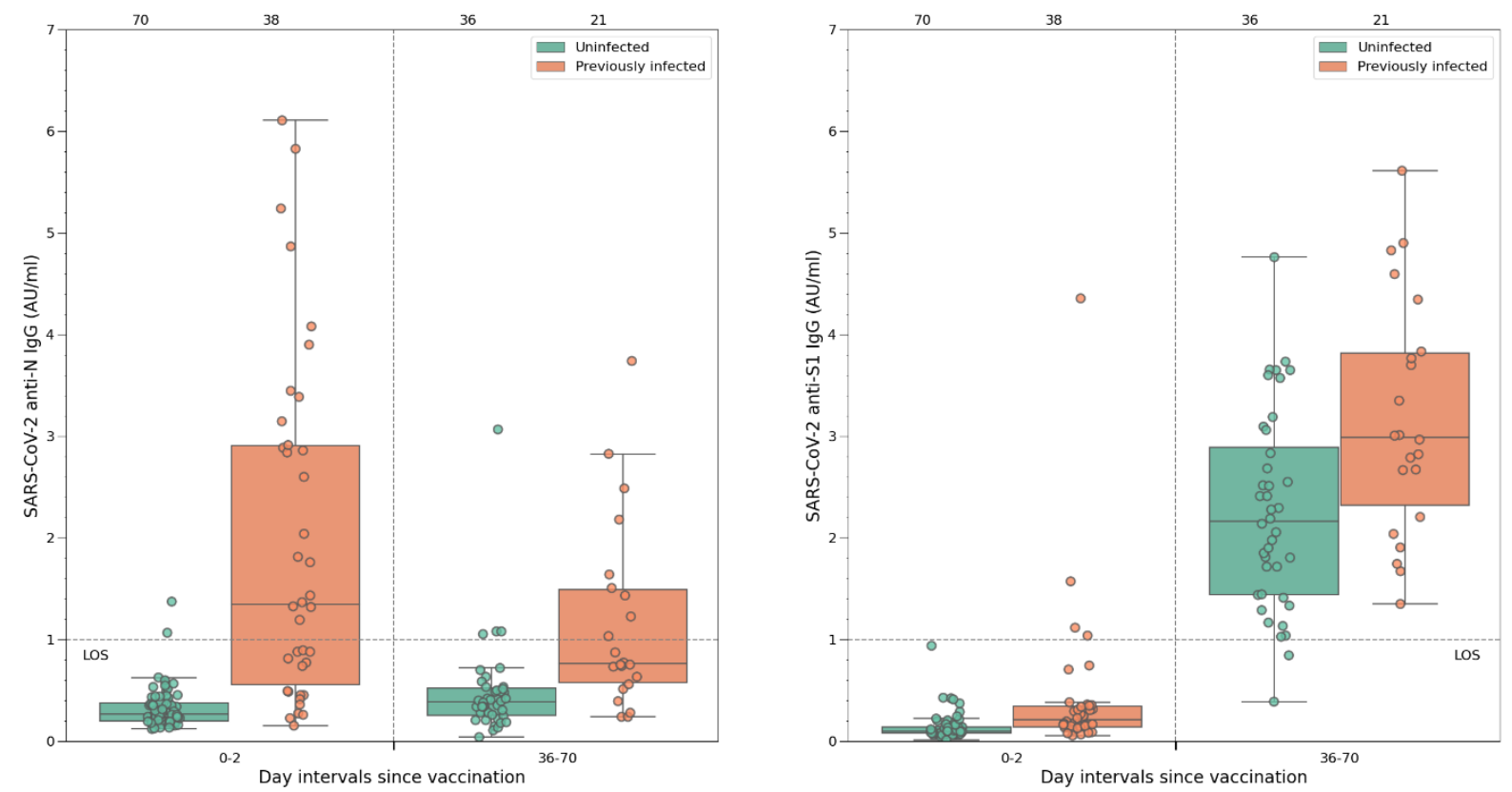

Figure 4. SARS-CoV-2 IgG levels for the uninfected and previously infected groups at the start of vaccination and 36-70 days after the first dose. Left panel: anti-N, right panel: anti-S1 IgG antibodies determined on nucleocapsidonly and S1-only plates. Apart from the concentration of coated antigens, for this measurement we used the same assay ingredients and protocol as that in the CE-marked commercial version. If multiple measurements were done for a participant within these intervals, only the largest value is shown. 
To verify whether the significant difference between antibody levels measured with the N+S1 combined commercial assay at the start of Period 2 (36-70 days after vaccination) is due to high maintained anti-N IgG values in the previously infected group, we remeasured the majority of samples collected at the baseline and those collected for Period 2, with the ingredients of the commercial assay, except that the plates were coated separately with N and S1 proteins according to the procedure described in the Methods section. We observe an overall decrease in anti-N $\operatorname{IgG}$ levels compared to the baseline (Figure 4 left panel), while the difference of anti-S1 IgG levels between the uninfected and previously infected groups remains significant ( $\mathrm{p}=0.0107$, Figure 4 right panel).

The reduced sensitivity of the assay at the baseline for anti-S1 IgG in the previously infected group, compared to that of the anti- $\mathrm{N}$ assay, cannot be explained by the difference in antigen size alone, since for a hypothetical case of a patient producing anti-N and anti-S1 antibodies of equal concentration and affinities, the size difference would decrease the signal of anti-S1 antibodies by $40 \%$ at most, corresponding to the $1 \mu \mathrm{g} / \mathrm{ml}$ coating solution containing less S1 proteins (1.06 fmol/well N protein versus $0.65 \mathrm{fmol} /$ well S1 protein). It is possible that patients produce anti$\mathrm{S} 1$ antibodies that bind with affinities below the threshold our assay can detect, and these antibodies can be detected with other assays. However, high affinity anti-S1 antibodies should have an important role in ensuring protection from infection, since a subset of these would be the most potent in preventing cell attachment. Only long-term follow-up studies can show if antibody levels measured with this assay are in good agreement with the level of protection amongst the population, especially in various population groups.

Figure $\mathrm{S} 1$ shows the change in measured SARS-CoV-2 IgG values grouped according to the gender of participants and their previous infection status. We observe no significant difference between the immune response of male and female participants, the resulting deviations among the previously infected group can be due to the small sample size for male participants. However, the age distribution shows different behavior based on post-vaccination immune response among the previously infected and uninfected groups, as shown in Figure S2. Among the uninfected group, antibody levels increase fastest within the young cohort (age groups 21-30 and 31-40). Among the previously infected group, the participants aged over 50 years have larger baseline antibody levels and their post-vaccine immune response is significant enough to keep antibody levels higher than those measured for the groups aged 21-50 at the end of Period 1 and even 36-70 days post-vaccination, although the number of data points is much smaller for this period. As post-infection antibody levels are correlated with disease severity, which is also correlated with age, it is possible that the observed post-vaccination humoral immune response of previously infected older participants is stronger due to the larger baseline antibody levels mounted as a response to more severe symptoms compared to the younger population.

\section{Discussion}

Our results show a robust humoral immune response that mounts gradually after the first BNT162b2 vaccine dose for the group previously uninfected with SARS-CoV-2, and a much stronger immune response within 7-14 days after the first dose for the previously infected group, in line with recent data from other cohorts of healthcare workers. ${ }^{17}$ For the previously infected group, the booster dose slightly elevates the SARS-CoV-2 anti-S1 antibody levels further, and we do not see the levels of the two groups converging at the beginning of Period 2 of our study. It remains to be seen if antibody level kinetics remains significantly different between the two groups over the period of several months. The kinetics data obtained within the first three weeks for the previously infected group suggests that a SARS-CoV-2 infection followed by a single BNT162b2 vaccine dose produces larger quantities of strongly binding anti-spike $1 \mathrm{IgG}$ antibodies than two BNT162b2 doses three weeks apart in previously uninfected individuals. In order to maximize antibody levels produced by uninfected vaccinated individuals, it might be beneficial to delay the second dose by a few weeks. The optimal timeframe could be determined by longitudinal evaluation of anti-S1 levels in a large cohort of previously uninfected healthy individuals who only get a single vaccine dose. Once the distribution of anti-spike IgG levels in the group declines to levels similar to that of the baseline levels of previously infected individuals, the administration of the second dose would likely induce a similar immune response to that of the previously infected group. However, this approach might reduce protection for immunocompromised individuals, as recently shown by the Covid-IP project (unpublished results to date, see https://www.immunophenotype.org/index.php/sample-page/vaccination-of-cancer-patients/immune-efficacy-ofbnt162b2-vaccine/), with an unknown increase of infection risk even among a healthy population, as the minimal amount (and quality) of circulating antibodies necessary for protective immunity against SARS-CoV-2 infection is yet to be determined. Alternatively, if the aim is reaching herd immunity in a short timeframe, individuals with 
medRxiv preprint doi: https://doi.org/10.1101/2021.03.17.21253751; this version posted March 24, 2021. The copyright holder for this preprint (which was not certified by peer review) is the author/funder, who has granted medRxiv a license to display the preprint in perpetuity.

It is made available under a CC-BY-ND 4.0 International license .

previous record of SARS-CoV-2 infection could be safely immunized with a single BNT162b2 vaccine dose. Given the global shortage of available vaccines, and the urgent need to confer long-lasting immunity, similar balanced approaches might be needed in the future to optimize both vaccine distribution and the maximal length of acquired immunity against COVID-19 among various population groups.

\section{Other information}

Supplementary material available: Two figures showing longitudinal antibody response by gender of participants and age groups and three tables showing the determined p-values between all groups shown in Figure 1. Two tables with anonymized data for each sample are provided in an Excel format, containing ELISA measurement results and sample information (day after vaccination, gender and age).

\section{Acknowledgements}

The authors wish to thank all participants in this study. SNF is grateful to Zsolt Gego for IT assistance, Mihaela Naidin and Timea Torok for logistical support.

\section{Competing interests}

SNF is the CEO of a startup of Pro-Vitam Ltd, and head of the group that developed the combined S1+N ELISA assay, commercialized by the startup.

\section{Author contributions}

Assay development: MKo, KR, ZJ, GH, SNF

Study design: ES, NS, VB, ML, MF, AA, LT, SNF

Data curation: MKo, ES, VB, ML, MF, AA, DP, LT, SNF

Experiments: MKo, MKá, HG

Data analysis: MKo, KR, ZJ, IH, MKá, KDF, SNF

Manuscript: MKo, KR, ZJ, IH, ML, MS, AA, SNF

\section{Bibliography}

${ }^{1}$ Ralph R, Lew J, Zeng T, et al. 2019-nCoV (Wuhan virus), a novel Coronavirus: human-to-human transmission, travel-related cases, and vaccine readiness. J Infect Dev Ctries 2020; 14: 3-17.

${ }^{2}$ Grayson MH. The Immune Response: Basic and Clinical Principles. Annals of Allergy, Asthma \& Immunology 2006; 97: 268.

${ }^{3}$ Jiang J-C, Zhang Y. Serological antibody testing in the COVID-19 pandemic: their molecular basis and applications. Biochem Soc Trans 2020; 48: 2851-63.

${ }^{4}$ Strömer A, Rose R, Grobe O, et al. Kinetics of Nucleo- and Spike Protein-Specific Immunoglobulin G and of Virus-Neutralizing Antibodies after SARS-CoV-2 Infection. Microorganisms 2020; 8: 1572.

${ }^{5}$ Rodda LB, Netland J, Shehata L, et al. Functional SARS-CoV-2-Specific Immune Memory Persists after Mild COVID-19. Cell 2021; 184: 169-183.e17.

${ }^{6}$ Dan JM, Mateus J, Kato Y, et al. Immunological memory to SARS-CoV-2 assessed for up to 8 months after infection. Science 2021; 371: eabf4063. 
medRxiv preprint doi: https://doi.org/10.1101/2021.03.17.21253751; this version posted March 24, 2021. The copyright holder for this preprint (which was not certified by peer review) is the author/funder, who has granted medRxiv a license to display the preprint in perpetuity. It is made available under a CC-BY-ND 4.0 International license .

${ }^{7}$ Wajnberg A, Amanat F, Firpo A, et al. Robust neutralizing antibodies to SARS-CoV-2 infection persist for months. Science 2020; 370: 1227-30.

${ }^{8}$ Chen W, Zhang J, Qin X, et al. SARS-CoV-2 neutralizing antibody levels are correlated with severity of COVID19 pneumonia. Biomedicine \& Pharmacotherapy 2020; 130: 110629.

${ }^{9}$ Pierce CA, Preston-Hurlburt P, Dai Y, et al. Immune responses to SARS-CoV-2 infection in hospitalized pediatric and adult patients. Sci Transl Med 2020; 12: eabd5487.

${ }^{10}$ Seow J, Graham C, Merrick B, et al. Longitudinal observation and decline of neutralizing antibody responses in the three months following SARS-CoV-2 infection in humans. Nat Microbiol 2020; 5: 1598-607.

${ }^{11}$ Huang J, Cao Y, Du J, Bu X, Ma R, Wu C. Priming with SARS CoV S DNA and boosting with SARS CoV S epitopes specific for CD4+ and CD8+ T cells promote cellular immune responses. Vaccine 2007; 25: 6981-91.

${ }^{12}$ Hotez PJ, Bottazzi ME, Corry DB. The potential role of Th17 immune responses in coronavirus immunopathology and vaccine-induced immune enhancement. Microbes Infect 2020; 22: 165-7.

${ }^{13}$ Jiang DH, McCoy RG. Planning for the Post-COVID Syndrome: How Payers Can Mitigate Long-Term Complications of the Pandemic. J Gen Intern Med 2020; 35: 3036-9.

${ }^{14}$ Corey L, Mascola JR, Fauci AS, Collins FS. A strategic approach to COVID-19 vaccine R\&D. Science 2020; 368: 948-50.

${ }^{15}$ Houlihan CF, Beale R. The complexities of SARS-CoV-2 serology. Lancet Infect Dis 2020; 20: $1350-1$.

${ }^{16}$ Bettini E, Locci M. SARS-CoV-2 mRNA Vaccines: Immunological Mechanism and Beyond. Vaccines (Basel) 2021; 9: 147.

${ }^{17}$ Prendecki M, Clarke C, Brown J, et al. Effect of previous SARS-CoV-2 infection on humoral and T-cell responses to single-dose BNT162b2 vaccine. The Lancet 2021; published online Feb. DOI:10.1016/s0140-6736(21)00502-x.

${ }^{18}$ Manisty C, Otter AD, Treibel TA, et al. Antibody response to first BNT162b2 dose in previously SARS-CoV-2infected individuals. The Lancet 2021; published online Feb. DOI:10.1016/s0140-6736(21)00501-8.

${ }^{19}$ Krammer F, Srivastava K, Alshammary H, et al. Antibody Responses in Seropositive Persons after a Single Dose of SARS-CoV-2 mRNA Vaccine. N Engl J Med 2021; published online March 10. DOI:10.1056/nejmc2101667.

${ }^{20}$ Vogel AB, Kanevsky I, Che Y, et al. BNT162b vaccines protect rhesus macaques from SARS-CoV-2. Nature $2021 ;:$ 10.1038/s41586-021-03275-y.

${ }^{21}$ Dai L, Gao GF. Viral targets for vaccines against COVID-19. Nat Rev Immunol 2020; 21: 73-82.

${ }^{22}$ Safety and Efficacy of the BNT162b2 mRNA Covid-19 Vaccine. N Engl J Med 2021; published online Feb 17. DOI:10.1056/nejmc2036242.

${ }^{23}$ Mulligan MJ, Lyke KE, Kitchin N, et al. Publisher Correction: Phase I/II study of COVID-19 RNA vaccine BNT162b1 in adults. Nature 2021; 590: E26.

${ }^{24}$ Sahin U, Muik A, Derhovanessian E, et al. Publisher Correction: COVID-19 vaccine BNT162b1 elicits human antibody and $\mathrm{T}_{\underline{H}} \underline{1} \mathrm{~T}$ cell responses. Nature 2021; 590: E17.

${ }^{25}$ Dagan N, Barda N, Kepten E, et al. BNT162b2 mRNA Covid-19 Vaccine in a Nationwide Mass Vaccination Setting. N Engl J Med 2021; published online Feb 24. DOI:10.1056/nejmoa2101765. 
medRxiv preprint doi: https://doi.org/10.1101/2021.03.17.21253751; this version posted March 24, 2021. The copyright holder for this preprint (which was not certified by peer review) is the author/funder, who has granted medRxiv a license to display the preprint in perpetuity.

It is made available under a CC-BY-ND 4.0 International license .

\section{Supplementary Material}

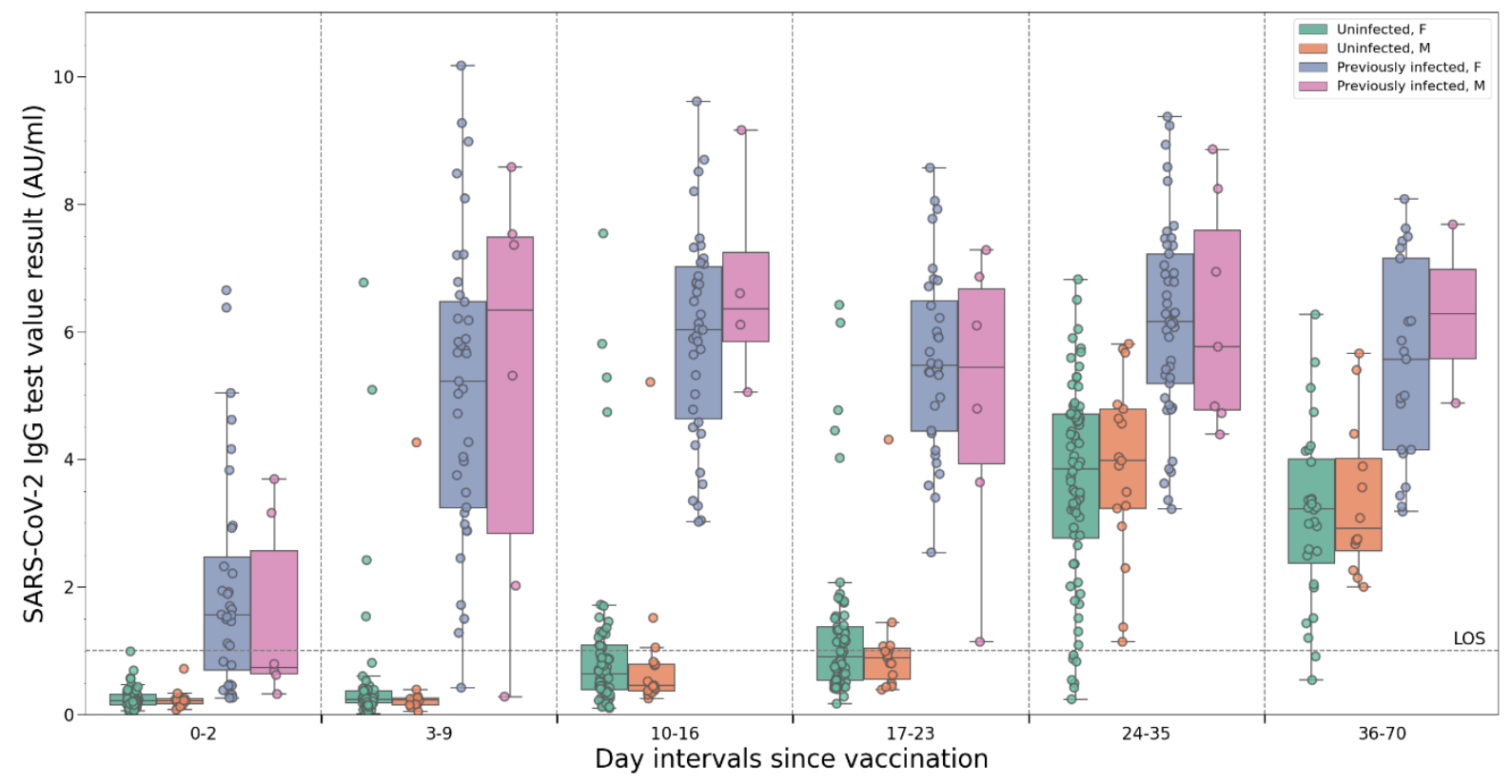

Figure S1. Longitudinal change of determined SARS-CoV-2 IgG values grouped according to the gender and previous infection status of the participants.

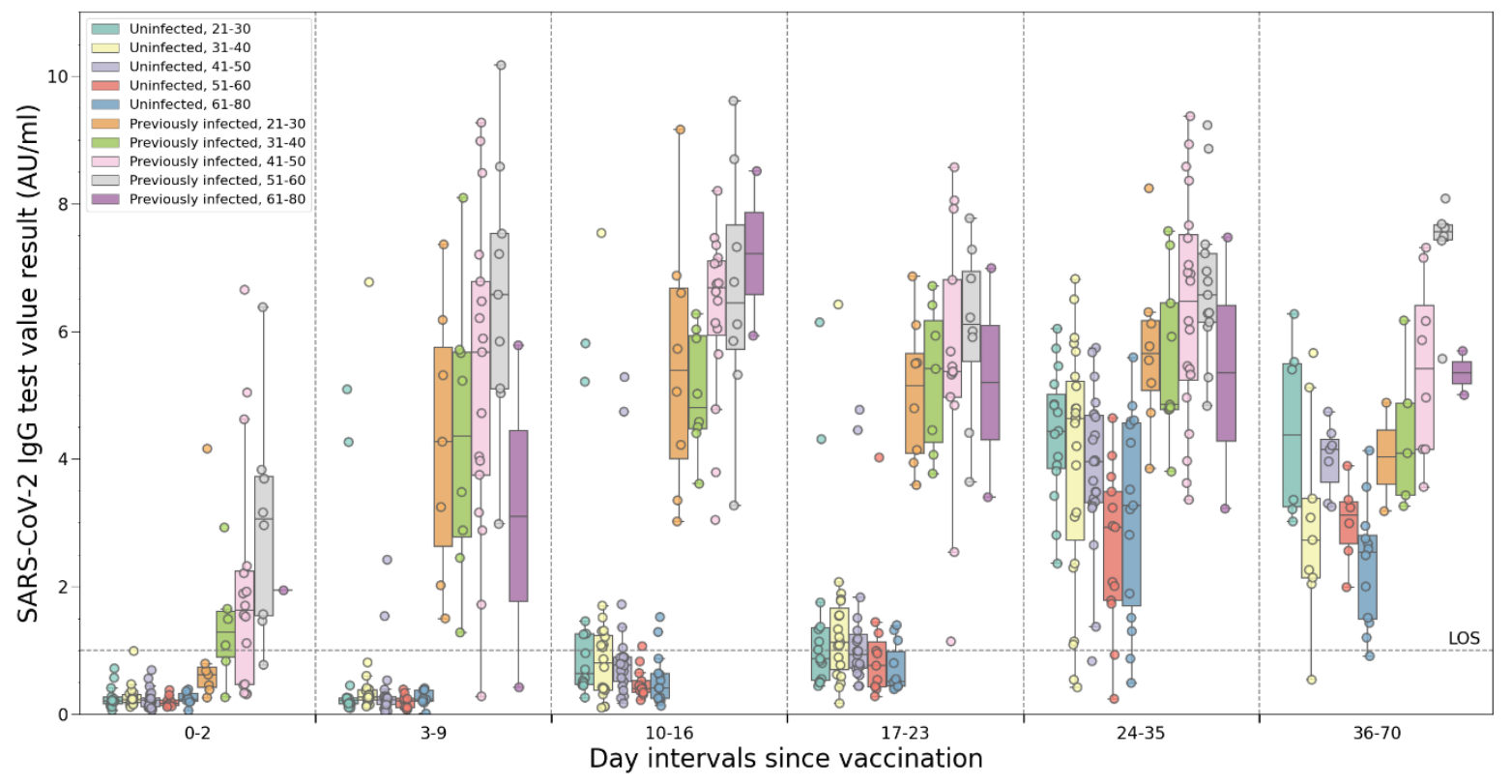

Figure S2. Longitudinal change of determined SARS-CoV-2 IgG values based on age groups and previous infection status of the participants. 
medRxiv preprint doi: https://doi.org/10.1101/2021.03.17.21253751; this version posted March 24, 2021. The copyright holder for this preprint (which was not certified by peer review) is the author/funder, who has granted medRxiv a license to display the preprint in perpetuity.

It is made available under a CC-BY-ND 4.0 International license.

Table S1. p-values determined between the previously infected and uninfected groups at different day intervals shown in Figure 1.

\begin{tabular}{|l|l|l|l|l|l|l|}
\hline $\begin{array}{l}\text { Previously infected / } \\
\text { uninfected }\end{array}$ & $\mathbf{0 - 2}$ & $\mathbf{3 - 9}$ & $\mathbf{1 0 - 1 6}$ & $\mathbf{1 7 - 2 3}$ & $\mathbf{2 4 - 3 5}$ & $\mathbf{3 6 - 7 0}$ \\
\hline $\mathbf{0 - 2}$ & $<0.0001$ & $<0.0001$ & $<0.0001$ & $<0.0001$ & $<0.0001$ & $<0.0001$ \\
\hline $\mathbf{3 - 9}$ & $<0.0001$ & $<0.0001$ & $<0.0001$ & $<0.0001$ & $<0.0001$ & $<0.0001$ \\
\hline $\mathbf{1 0 - 1 6}$ & 0.0030 & $<0.0001$ & $<0.0001$ & $<0.0001$ & $<0.0001$ & $<0.0001$ \\
\hline $\mathbf{1 7 - 2 3}$ & 0.0279 & $<0.0001$ & $<0.0001$ & $<0.0001$ & $<0.0001$ & $<0.0001$ \\
\hline $\mathbf{2 4 - 3 5}$ & $<0.0001$ & 0.00088 & $<0.0001$ & $<0.0001$ & $<0.0001$ & $<0.0001$ \\
\hline $\mathbf{3 6 - 7 0}$ & 0.00051 & $<0.0001$ & $<0.0001$ & $<0.0001$ & $<0.0001$ & $<0.0001$ \\
\hline
\end{tabular}

Table S2. p-values determined between the previously infected groups at different day intervals shown in Figure 1.

\begin{tabular}{|l|l|l|l|l|l|l|}
\hline $\begin{array}{l}\text { Previously infected / } \\
\text { previously infected }\end{array}$ & $\mathbf{0 - 2}$ & $\mathbf{3 - 9}$ & $\mathbf{1 0 - 1 6}$ & $\mathbf{1 7 - 2 3}$ & $\mathbf{2 4 - 3 5}$ & $\mathbf{3 6 - 7 0}$ \\
\hline $\mathbf{0 - 2}$ & 1 & $<0.0001$ & $<0.0001$ & $<0.0001$ & $<0.0001$ & $<0.0001$ \\
\hline $\mathbf{3 - 9}$ & $<0.0001$ & 1 & 0.0503 & 0.4268 & 0.015 & 0.369 \\
\hline $\mathbf{1 0 - 1 6}$ & $<0.0001$ & 0.0503 & 1 & 0.1424 & 0.5957 & 0.2911 \\
\hline $\mathbf{1 7 - 2 3}$ & $<0.0001$ & 0.4268 & 0.1424 & 1 & 0.0369 & 0.832 \\
\hline $\mathbf{2 4 - 3 5}$ & $<0.0001$ & 0.015 & 0.5957 & 0.0369 & 1 & 0.1229 \\
\hline $\mathbf{3 6 - 7 0}$ & $<0.0001$ & 0.369 & 0.2911 & 0.832 & 0.1229 & 1 \\
\hline
\end{tabular}

Table S3. p-values determined between the uninfected groups at different day intervals shown in Figure 1.

\begin{tabular}{|l|l|l|l|l|l|l|}
\hline Uninfected / uninfected & $\mathbf{0 - 2}$ & $\mathbf{3 - 9}$ & $\mathbf{1 0 - 1 6}$ & $\mathbf{1 7 - 2 3}$ & $\mathbf{2 4 - 3 5}$ & $\mathbf{3 6 - 7 0}$ \\
\hline $\mathbf{0 - 2}$ & 1 & 0.0556 & $<0.0001$ & $<0.0001$ & $<0.0001$ & $<0.0001$ \\
\hline $\mathbf{3 - 9}$ & 0.0556 & 1 & 0.0119 & 0.0001 & $<0.0001$ & $<0.0001$ \\
\hline $\mathbf{1 0 - 1 6}$ & $<0.0001$ & 0.0119 & 1 & 0.1963 & $<0.0001$ & $<0.0001$ \\
\hline $\mathbf{1 7 - 2 3}$ & $<0.0001$ & 0.0001 & 0.1963 & 1 & $<0.0001$ & $<0.0001$ \\
\hline $\mathbf{2 4 - 3 5}$ & $<0.0001$ & $<0.0001$ & $<0.0001$ & $<0.0001$ & 1 & 0.0789 \\
\hline $\mathbf{3 6 - 7 0}$ & $<0.0001$ & $<0.0001$ & $<0.0001$ & $<0.0001$ & 0.0789 & 1 \\
\hline
\end{tabular}


medRxiv preprint doi: https://doi.org/10.1101/2021.03.17.21253751; this version posted March 24, 2021. The copyright holder for this preprint (which was not certified by peer review) is the author/funder, who has granted medRxiv a license to display the preprint in perpetuity.

It is made available under a CC-BY-ND 4.0 International license .

The Excel spreadsheet with per-patient values used throughout this work can be downloaded from www.szilard.ro/files/covid_antibody_study.xlsx. 